\title{
Trace Element Levels and Socio-Demography of Pre-Teen Nigerians with Homozygous Sickle Cell Disorder
}

\author{
K. O. Shittu ${ }^{a}$, F. A. Egbeleke ${ }^{a}$ and A. A. Iyanda ${ }^{b^{*}}$ \\ ${ }^{a}$ Department of Medical Laboratory Sciences, College of Health Sciences, \\ Ladoke Akintola University of Technology, Osogbo, Nigeria. \\ ${ }^{b}$ Department of Chemical Pathology, College of Health Sciences, \\ Ladoke Akintola University of Technology, Osogbo, Nigeria.
}

Authors' contributions

This work was carried out in collaboration among all authors. Author KOS experimentation data analysis and interpretation author FAE data analysis author AAI study design and preparation of manuscript. The final manuscript has been read and approved by all authors.

Article Information

DOI: 10.9734/ARRB/2022/v37i230483

Open Peer Review History: This journal follows the Advanced Open Peer Review policy. Identity of the Reviewers, Editor(s) and additional Reviewers, peer review comments, different versions of the manuscript, comments of the editors, etc are available here: https://www.sdiarticle5.com/review-history/70210

Original Research Article

Received 05 May 2021

Accepted 01 July 2021 Published 05 February 2022

\section{ABSTRACT}

Objectives: Homozygous sickle cell disorder (SCD) children are known to have abnormal anthropometric parameters which mostly have been linked with altered zinc status. Alteration in trace element status which occurs from interaction between essential and non-essential elements has not been well studied in SCD. Therefore, the aim of the study is to relate concentrations of $\mathrm{Zn}$, $\mathrm{Cd}$, and $\mathrm{Pb}$ with anthropometric parameters. Moreover, it will be established if correlation (interaction) exists between zinc and these two non-essential elements.

Methods: Twenty-seven SCD patients and 25 age and sex-matched children with hemoglobin genotype HbAA served as test and control groups respectively. Anthropometric parameters and information on demography, dietary zinc status and socio-economic status were obtained. The plasma and red cells obtained from $5 \mathrm{~mL}$ of blood were used to determine zinc and heavy metal $(\mathrm{Pb}, \mathrm{Cd})$ levels respectively by atomic absorption spectrophotometry. Data were analyzed using Student's $t$-test, Chi- square test, and Pearson's correlation coefficient. $\mathrm{P}<0.05$ was considered significant.

Results: There were significant differences in the mean values of mid-upper-arm circumference, weight and BMI. On the other hand, there were no significant differences in mean values of head 
circumference, height and the trace elements in test and control groups. No association between trace elements and BMI as well as between dietary zinc content and socio-economic status was observed.

Conclusion: the result of the study suggests there is no correlation between the toxic metals and zinc, and it seems that toxic metals play no role in abnormal BMI that is a common feature of SCD.

Keywords: Anthropometric parameters; zinc; lead; cadmium; sickle cell disease.

\section{INTRODUCTION}

Sickle cell disease which occurs from genetic mutation in the hemoglobin-gene ultimately translates to synthesis of abnormal haemoglobin. The disorder is commonly found among people of tropical countries and it is transmitted in an autosomal recessive fashion [1]. In Nigeria, the prevalence of sickle cell homozygous state is about $3 \%$ of the population [2]. Growth retardation is a predominant feature of the disorder. Studies carried out by various teams revealed that by using anthropometric criteria as focus of study, significant stunting of growth was observed among patients of sickle cell disease (SCD) compared with unaffected controls of the same gender, age and socio-economic status. Data obtained from past studies have shown that not only growth retardation but other clinical features such as immunologic and nutritional abnormalities are associated with micro- and macronutrient deficiency among individuals with sickle cell anaemia (SCA) [3-5].

Delayed growth and maturation among individuals with SCA is associated with low plasma zinc [6]. Investigators have demonstrated that administration of micronutrient (example, $\mathrm{Zn}$ ) supplements to individuals with SCA led to improvement in growth [7]. These results, apart from demonstrating the benefits of nutrition in the management of SCA, provide further support to the hypothesis that some SCA-associated complications have as much nutritional underpinning as they do genetic, yet the role that trace element interaction (between toxic and essential metals) plays remains undetermined. Trace element interaction is capable of altering detrimentally the clinical status of essential trace element levels of which zinc is a member.

Currently the realization of the importance of micronutrients in disease management necessitates the need to study how heavy metals which interact with essential trace elements may affect anthropometric parameters in SCD patients. While there is yet no conclusive evidence for high lead $(\mathrm{Pb})$ or cadmium (Cd) burden in SCD patients, the ability of metals to interact makes this a possibility. That low level of one metal affects not only the bioavailability but also the physiologic function or degree of toxicity of another metal, is a recognized phenomenon [8]. A few of the mechanisms that result in trace element homeostasis are shared by both zinc and other bivalents. Attempts will be made through this study to understand the relationship between anthropometric parameters and plasma zinc, lead and cadmium levels in SCD pre-teen Nigerians.

\section{MATERIALS AND METHODS}

\section{Study design: Cross-sectional comparative study}

\section{Sampling technique: Convenience sampling}

Study Population: Research participants (25 control; 27 SCD children) consist of pre-teen male and female respondents. Specifically, children with homozygous sickle cell disorder already diagnosed by electrophoresis, that are in steady state and attending the paediatric sickle cell clinic/sickle cell outpatient clinic at Obafemi Awolowo University and LAUTECH Teaching Hospitals for medical check-up were recruited. The control group consisted of healthy preteenagers with haemoglobin genotype $\mathrm{HbAA}$ matched for age and sex, randomly selected from primary schools within lle-Ife.

Inclusion criteria: Patients that were stable (in steady state), without vaso-occlusion at least 3 months to the date of recruitment were included. Healthy individuals with $\mathrm{HbAA}$ were used as control group. Participants were of both genders: male and female in the ratio of $1: 1$ [since the prevalence of SCD is equal in both sexes].

Exclusion criteria: Those without genotype records as well as SCD children in vasoocclusion crises were excluded. Moreover, all children known to have chronic medical conditions (such as HIV, tuberculosis and chronic renal failure) as well as subjects on drug (such 
as captoril, omeprazole, hydroxyurea) were excluded. All children with postural deformity that affect height were excluded from the study.

Sample collection and trace element estimation: Laboratory-ware used was cleansed according to standard procedure as described in Elemental Analysis Manual of United State Department of Health and Human Services. Three milliliters of venous blood was collected from all participants into heparinized bottles. Each sample was centrifuged at 1500 revolution per minutes for 5 minutes. Plasma was kept at 20 degree Celsius until required for analysis. Determination of trace element levels was carried out using Atomic Absorption Spectrometry.

Anthropometric measurement: Weight in kilograms was taken with subjects in their clothes made of light fabric barefoot, holding onto nothing, using a normal bathroom standing scale [AL Hana Medical weighing equipment, Dubai]. Recordings were made to the nearest $0.5 \mathrm{~kg}$.

Standing height in centimeters $(\mathrm{cm})$ was measured with a stadiometer [Indo Surgicals Private Limited, New Delhi, India]. Measurements were without shoes, both feet flat on the ground and apposed at the medial malleoli. Recordings were made to the nearest $0.5 \mathrm{~cm}$.

The BMI was calculated by the formula: $\mathrm{BMI}=$ Weight $(\mathrm{Kg}) /$ height $\left(\mathrm{m}^{2}\right)$. World Health Organization and Centers for Disease Control classification was employed to classify BMI into underweight as BMI less than the 5th percentile, healthy weight as BMI of 5th up to the 85th percentile, overweight as BMI of 85th to less than the 95th percentile and obese as BMI equal to or greater than the 95th percentile for age and gender [9].

Head and mid-upper arm (MUA) circumference was obtained. Measurement of the head circumference was taken to the nearest $0.1 \mathrm{~cm}$ with a non-stretchable tape using the glabella and the occiput as the landmarks [10].

Instrument of data collection: Pre-tested, structured questionnaire was administered. It consisted of different sections namely; demography [Information regarding age, gender, parents' occupation and education]. Socioeconomic class was determined as described by Oredugba and Savage [11] and Oyedeji [12]. Dietary zinc content was obtained using the classification described by Temiye et al. [13]. For a child below the age of 10 years the assistance of the mother was employed to carry out the interview.

\subsection{Stastical Analysis}

The data obtained from the trace element analyses and anthropometric measurements were analyzed with Statistical Package for Social Sciences (SPSS). The data was expressed in mean \pm Standard Deviation (SD). The difference among the means was analyzed by Student's $t$ test. Pearson`s chi-square test was also used to establish relationship between dietary zinc content, or socio-economic status and BMI percentiles. Pearson's correlation coefficient was employed to correlate trace element levels with anthropometric parameters. $p$ values $<0.05$ were considered statically significant.

\section{RESULTS}

Presented below are the results of 52 children enrolled in this study, comprising of 25 subjects as the control group, and 27 subjects as the test group. Table 1 shows the mean distribution and comparison of age as well as anthropometric markers between the test and control groups. There were significant decreases in the mean values of middle upper arm circumference (MUA), weight and body mass index (BMI) of test group when compared to control group $(p<0.05)$. However, there were no significant differences in the mean values of age, head circumference $(\mathrm{HC})$ and height of the test group when compared to that of the control $(p>0.05)$. Table 2 shows the comparison of mean values of essential and non-essential trace elements. There were no significant differences in the mean values of zinc, lead and cadmium of the test group when compared to the control group $(p>0.05)$. Table 3 shows the frequency distribution of dietary zinc content; socioeconomic status; BMI percentiles of control and sickle cell children. In addition, statistical analysis of qualitative data and trace elements shows that there was non-significant correlation between zinc and lead $(r=-0.088, p=0.663)$ as well as between zinc and cadmium ( $r=-0.270, p=0.300)$ in SCD children using Pearson's correlation coefficient. Also there was no association between lead and $\mathrm{BMI}$ prcentiles $(\mathrm{X} 2=1.762$, $\mathrm{p}=0.415)$, as well as cadmium and $\mathrm{BMI}(\mathrm{x} 2=$ $0.241, p=0.623$ ). Using Chi-square there was no association between dietary zinc content and BMI percentile $(x 2=8.252, p=0.08)$. There was no 
association between dietary zinc content and socio-economic status $(x 2=3.758, p=0.440)$.

\section{DISCUSSION}

Children with sickle cell disease had low anthropometric indices when compared to the controls and this is evident by significantly low $\mathrm{BMI}$ and weight. Low BMI is a peculiarity of sickle cell disease that has been linked with abnormality in long and thin bone growth. That such abnormality is not the basis of the significantly low level of BMI in sickle cell disease children can be postulated from the results of height; there was no significant difference in heights of SCD children and controls (Table 1). The significant decrease in weight and body mass index (BMI) of test group when compared to that of control group could be due to the additional metabolic demand of SCD, although the present finding is consistent with those of previous studies [9, 14-16]. Meanwhile others like Oredugba and Savage [11] reported that in Nigerian sickle cell children, height and weight were not significantly different in both groups except at 18 years when SCD subjects weighed less than controls. The differences in the results of the various studies could be due to differences in subject selection. Nikhar et al. [14] selected children aged $5-18$ years $(n=50)$; Oredugba and Savage [11] recruited children between the ages of 1-18 years $(n=177)$ while the participants of Odetunde et al [9] study were 6-20 years of age $(n=40)$.

Table 1. Comparison of age and anthropometric markers between the test and the control group

\begin{tabular}{llll}
\hline Parameters (Units) & Control group (Mean \pm SD) & Test group (Mean \pm SD) & P-value \\
\hline Age $($ years) & $10.28 \pm 4.68$ & $8.15 \pm 4.33$ & 0.094 \\
MUA $(\mathrm{cm})$ & $8.26 \pm 1.68$ & $7.33 \pm 1.09$ & $0.021^{*}$ \\
HC $(\mathrm{cm})$ & $20.76 \pm 0.88$ & $20.87 \pm 1.12$ & 0.696 \\
Height $(\mathrm{cm})$ & $120.80 \pm 20.01$ & $121.04 \pm 17.47$ & 0.066 \\
Weight $(\mathrm{kg})$ & $31.30 \pm 12.13$ & $23.24 \pm 9.33$ & $0.009^{*}$ \\
BMI $\left(\mathrm{kg} / \mathrm{m}^{2}\right)$ & $17.16 \pm 2.46$ & $15.07 \pm 2.51$ & $0.004^{*}$ \\
\hline
\end{tabular}

LEGEND: Data presented as mean \pm standard deviation. *Means significant at $p$-value $<0.05$. Abbreviations: MUA; Middle upper arm circumference, HC; Head circumference, BMI; body mass index

Table 2. Comparison of plasma zinc, blood lead and cadmium of test and control groups

\begin{tabular}{llll}
\hline Parameters (Units) & Control group (Mean \pm SD) & Test group (Mean \pm SD) & P-value \\
\hline Zinc $(\mathrm{ppm})$ & $0.08 \pm 0.11$ & $0.12 \pm 0.19$ & 0.394 \\
Lead $(\mathrm{ppm})$ & $0.06 \pm 0.04$ & $0.28 \pm 0.67$ & 0.105 \\
Cadmium $(\mathrm{ppm})$ & $0.92 \pm 2.74$ & $0.45 \pm 0.59$ & 0.387 \\
\hline
\end{tabular}

Table 3. Frequency distribution of dietary zinc content; socio-economic status; BMI percentiles of control and sickle cell children

\begin{tabular}{lllll}
\hline & & & Control & $\begin{array}{l}\text { SCD } \\
\text { children }\end{array}$ \\
\hline Dietary zinc & High & Absolute/Relative frequency & $3 / 12.0 \%$ & $5 / 18.5 \%$ \\
content & Low & Absolute/Relative frequency & $8 / 32.0 \%$ & $7 / 26.0 \%$ \\
& Moderate & Absolute/Relative frequency & $14 / 56.0 \%$ & $15 / 55.5 \%$ \\
Socio-economic & High & Absolute/Relative frequency & $21 / 84 \%$ & $19 / 70.4 \%$ \\
status & Low & Absolute/Relative frequency & $0 / 0.0 \%$ & $2 / 7.4 \%$ \\
& Medium & Absolute/Relative frequency & $4 / 16.0 \%$ & $6 / 22.2 \%$ \\
BMI percentiles & Normal & Absolute/Relative frequency & $22 / 88.0 \%$ & $17 / 63.0 \%$ \\
& Obese & Absolute/relative frequency & $2 / 8.0 \%$ & $1 / 3.7 \%$ \\
& Underweight & Absolute/relative frequency & $1 / 4.0 \%$ & $9 / 33.3 \%$ \\
\hline
\end{tabular}


Findings from this study showed there were no significant differences in the mean values of zinc, lead and cadmium of the test group when compared to the control group (Table 2). This is contrary to the observation of Temiye et al. [13], who reported a significant decrease in serum zinc concentrations of sickle cell patients when compared to the control group. They opined that zinc being an essential constituent of red blood cells as well as an antioxidant occurs at depleted levels in SCD state. The alteration probably arises from repeated hemolysis of continuous oxidative stress due to sickle cell reduction-oxidation imbalance, during which zinc is utilized, resulting in its increased demand [17]. Of the 27 SCD children, 25 were of medium or high economic status and 20 indicated moderate to high dietary zinc intake. On the other hand, in a control population of 25 non-sickle cell disease children all 25 were of medium/high economic status and 17 with history of moderate to high dietary zinc intake. Yet the zinc levels of both test and controls were not significantly different

The research findings in the past decade that identified ways of improving nutritional contents of SCD children (reference) might have been the basis of non-significant difference in zinc status in SCD children compared with controls. This probably suggests that such efforts are being translated into better day-to-day management of the disease. Although there is need to exercise caution in coming to such conclusion, prior to the conduct of a study of a larger sample size. Moreover, the zinc result of SCD children in the present study could have occurred from the fact that all the SCD children were in steady state. They had not experienced vaso-occlusion crises, severe anaemia requiring transfusion and other major medical events commonly linked with SCD three months prior to their inclusion in the study. Many studies in which low zinc levels were observed in SCD children did not include such medical events in their exclusion criteria.

There was no evidence of increased toxic metal level in SCD children as non-significant difference was observed in SCD children and control. This suggests that these elements- $\mathrm{Pb}$ and $\mathrm{Cd}$ - known for their high degree of toxicity play no role on many of the complications (e.g. low BMI) associated with sickle cell disease. This is further supported by lack of association between each of the toxic metals and BMI as well as plasma zinc levels.
Socioeconomic status is one of the major factors that directly affect treatment and access to health care system in a developing country. Adherence and attendance to follow-up visits are often affected by the low family income, especially by the distance between the home and the specialized services facilities. This phenomenon is aggravated when it comes to patients with chronic disease in a situation of dependence, as is the case of children with sickle cell disease [18]. Present study shows no association between zinc dietary content and socio-economic status with majority of test subjects having medium to high socio-economic status as well as at least moderate zinc dietary content.

\section{CONCLUSION}

The evaluation of selected trace element levels and anthropometric markers of pre-teenagers with homozygous sickle cell disorder from this study shows that, there is no difference between trace metals, zinc, lead and cadmium in both test and control group. Toxic metals play no roles on SCD children complication e.g. low BMI because there is no any association between heavy metals, zinc and BMI. Zinc levels of SCD children were not difference from control group probably because they were in steady state as well as dietary zinc content which has no association with their socio economic status.

\section{LIMITATION OF STUDY}

The use of convenient sample technique as well as small sample size is a limitation of the study. In addition, pre-pubertal children were used for the study. Whether puberty would have modified the result outcome will need to be determined.

\section{DISCLAIMER}

The products used for this research are commonly and predominantly use products in our area of research and country. There is absolutely no conflict of interest between the authors and producers of the products because we do not intend to use these products as an avenue for any litigation but for the advancement of knowledge. Also, the research was not funded by the producing company rather it was funded by personal efforts of the authors. 


\section{CONSENT AND ETHICAL CONSIDE- RATION}

Ethical clearance was obtained from the Ministry of Health, Osun State, Nigeria. Written consent was obtained from parents/ guardians. The assent of children 9 years and above was sought and obtained. Anonymity of information obtained was maintained.

\section{COMPETING INTERESTS}

Authors have declared that no competing interests exist.

\section{REFERENCES}

1. Mwalswelo RO, Mawala W, IVERSEN po, et al. Sickle cell disease and malaria: decreased exposure and asplenia can modulate the risk from Plasmodium falciparum. Malaria J. 2020;19:165 Available: http://doi.org/10.1186/s12936020-03212-w

2. Adekile AD, Adeodu OO. Sickle cell disease clinical phenotype in children from south-Weastern, Nigeria. Niger J Clin Pract. 2007;18: 95-101.

3. Allali $S$, Dietrich $\mathrm{C}$, Machavoine $\mathrm{F}$, Rignault-Bricard R, Brousse V, de Montalembert M, et al. Innate-like T cells in children with sickle cell disease. PLoS One. 2019;14(6):e0219047.

DOI:10.1371/journal.pone.0219047.ecollec tion 2019.

4. Kapoor S, Little JA, Pecker LH. Advances in the treatment of sickle cell disease. Mayo Clin Proc. 2018;93(12):1810-1824. DOI: 10.1016/j.mayocp.2018.09.001.

5. Ngo UM SS, Seungue J, Alima AY, Mbono $R$, Mbassi H, Chelo D, Koki PO. A cross sectional study of growth of children with sickle cell disease, aged 2 to 5 years in Yaounde, Cameroon. Pan Afr Med J. 2019;34:85.

DOI:10.11604/pamj.2019.4.85.16432. eCollection 2019.

6. Leonard MB, Zemel BS, Kawchak DA, Ohene FK, Virginia VA. Plasma zinc status, growth and maturation in children with sickle cell disease. J Pediat 2015; 132:467-471.

7. Swe KM, Abas AB, Bhardwaj A, Barua A, Nair NS. Zinc supplements for treating thalassaemia and sickle cell disease.
Cocharane Database Syst Rev. 2013; (6):CD009415.

DOI: 10.1002/14651858.Cd009415.pub2.

8. Adams $W$, Blust R, Dwyer R, Mount D, Nordheim E, Rodriguez PH, Spry D. Bioavailability assessment of metals in freshwater environments: a historical review. Environ Toxicol Chem. 2020; 39(1):48-59.

DOI:10.1002/etc.4558

9. Odetunde OI, Chinawa JM, Achigbu KI, Achigbu EO. Body mass index and other anthropometric variables in children with sickle cell anaemia. Pak J Med Sci. 2016; 32(2): 341-346.

DOI: 10.12669/pjms.322.9046

10. Senbanjo IO, Oshikoya KA, Salisu M, Diaku-Akinwumi IN. Head circumference of children with sickle cell disease in Lagos, Nigeria. Pan Afr Med J. 2016;25:

DOI: 10.11604/pamj.2016.25.4.8030

11. Oredugba FA, Savage KO. Anthropometric finding in Nigerian children with sickle cell disease. Pediatr Dent. 2002;24(4):321-5.

12. Oyedeji GA. Socio-economic and cultural background of hospitalized children in llesha. Nigeria J Paediatr. 1985;12:111117.

13. Temiye EO, Duke ES, Owolabi MA, Renner JK. Relationship between painful crisis and serum zinc level in children with sickle cell anaemia. Anemia. 2011;69:8586.

14. Nikhar HS, Meshram SU, Shinde GB. An anthropometric and hematological comparison of sickle cell disease children from rural and urban areas. Indian $\mathrm{J}$ Hum Genet. 2012;18(1):40-42.

15. VanderJagt DJ, Okolo SN, Rabasa AI, Glew $\mathrm{RH}$. Bioelectrical impedance analysis of the body composition of Nigerian children with sickle cell disease. J Trop Pediatr. 2000;46:67-72.

16. Barden EM, Kawchak DA, Ohene-Frempong $\mathrm{KH}$, Stallings VA, Zemel BS. Body composition in children with sickle cell disease. Am J Clin Nutr. 2002;76:218-25.

17. Hasanato RM. Zinc and antioxidant vitamin deficiency in patients with severe sickle cell anemia. Ann Saudi Med. 2006; 26:17-21. 
18. Boulet SL, Yanni EA, Creary MS, Olney RS. Health status and healthcare use in a national sample of children with sickle cell disease. Am J Prev Med. 2010; 38:528-535.

(0) 2022 Shittu et al.; This is an Open Access article distributed under the terms of the Creative Commons Attribution License (http://creativecommons.org/licenses/by/4.0), which permits unrestricted use, distribution, and reproduction in any medium, provided the original work is properly cited.

\section{Peer-review history:}

The peer review history for this paper can be accessed here: https://www.sdiarticle5.com/review-history/70210 